\title{
AVALIAÇÃO DE ATRIBUTOS FÍSICOS E ESTOQUES DE CARBONO E NITROGÊNIO EM SOLOS COM QUEIMA E SEM QUEIMA DE CANAVIAL ${ }^{(1)}$
}

\author{
Edgar Fernando de Luca(2), Christian Feller ${ }^{(3)}$, Carlos Clemente \\ Cerri $^{(4)}$, Bernard Barthès ${ }^{(3)}$, Vicente Chaplot ${ }^{(5)}$, Dinailson Correa \\ Campos $^{(4)} \&$ Célio Manechini ${ }^{(6)}$
}

\begin{abstract}
RESUMO
O Brasil é o maior produtor mundial de cana-de-açúcar, de modo que mudanças no seu manejo podem afetar sobremaneira o ambiente. Há quase um século, as pesquisas são baseadas em áreas sob queima da biomassa foliar (palhada) dessa cultura. Mas a supressão da queimada é um novo conceito no manejo da palhada. Portanto, há poucos resultados sobre o manejo desse material. O objetivo do estudo foi comparar teores de $\mathrm{C}$ e $\mathrm{N}$ e estabilidade de agregados e densidade do solo nos manejos com queima (Cq) e sem queima (Sq) da palhada. Estudou-se um solo argiloso (Latossolo Vermelho $=$ LVdf) e dois solos arenosos (Argissolo VermelhoAmarelo = PVAd e Neossolo Quartzarênico $=$ RQo) submetidos aos manejos Cq e Sq. Em cada solo foi estabelecida uma área experimental em blocos ao acaso com seis repetições. A quantidade de palhada adicionada em três colheitas foi $40 \mathrm{t} \mathrm{ha}^{-1} \mathrm{em}$ matéria seca e, um ano após a terceira colheita, a acumulação foi $4,5 \mathrm{t} \mathrm{ha}^{-1}(11 \%)$ no LVdf e 3,6 $\mathrm{t} \mathrm{ha}^{-1}(9 \%)$ no RQo. Isso representou 1,60 e 1,35 $\mathrm{t} \mathrm{ha}^{-1} \mathrm{em} \mathrm{C} \mathrm{e} \mathrm{0,022} \mathrm{e}$ $0,021 \mathrm{t} \mathrm{ha}^{-1} \mathrm{em} \mathrm{N}$, respectivamente. Houve aumento no teor de $\mathrm{C}$ nos solos $\mathrm{Sq}$, concorrendo em seqüestro de $C$ na camada $0-20 \mathrm{~cm}$ de 6,3 e $4,7 \mathrm{t} \mathrm{ha}^{-1}$, respectivamente em LVdf e RQo. Assim, a taxa de seqüestro de C no compartimento cobertura + solo $(0-20 \mathrm{~cm})$ foi de 2,63 e $2,02 \mathrm{t} \mathrm{ha}^{-1}$ ano $^{-1}$ no LVdf e RQo, respectivamente. Também houve aumento no teor de macroagregados em solos Sq comparados a solos Cq: 814 e $693 \mathrm{~g} \mathrm{~kg}^{-1}$ no LVdf e 516 e $420 \mathrm{~g} \mathrm{~kg}^{-1}$ no RQo. Ocorreu compactação superficial no PVAd e RQo em decorrência do uso de máquina colhedora em solo Sq. Nos solos estudados, o manejo sem queima da
\end{abstract}

\footnotetext{
(1) Parte da Tese de Doutorado do primeiro autor (FAPESP 98/12648-3 e 98/13281-6). Recebido para publicação em outubro de 2005 e aprovado em novembro de 2007.

${ }^{(2)}$ Pesquisador do Instituto Florestal de São Paulo - IF. Horto Navarro de Andrade, CEP13500-970 Rio Claro (SP). E-mail: efluca@gmail.com

(3) Pesquisador do Institut de Rechèrche pour le Dévelopment - IRD. França. E-mails: feller@ird.mg; barthes@mpl.ird.fr

(4) Pesquisador do Centro de Energia Nuclear na Agricultura, Universidade de São Paulo - CENA/USP. Av. Centenário 303 , CEP 13400-970 Piracicaba (SP). E-mail: cccerri@cena.usp.br; dccampos@cena.usp.br

(5) Pesquisador IRD/SBEEH - University of Kwazulu - Natal Box X01 Scootsville, 3209 África do Sul. E-mail: chaploto@ukzn.ac.za

(6) Pesquisador da Usina São Martinho S/A. Fazenda São Martinho, CEP 14850-000 Pradopólis (SP). E-mail: celio.manechini@saomartinho.ind.br
} 
cana-de-açúcar resultou em melhorias nas propriedades dos solos e promoveu seqüestro de $\mathrm{C}$ e $\mathrm{N}$ na cobertura e nas camadas superficiais dos solos.

Termos de indexação: cobertura vegetal, estabilidade estrutural, queimada, colheita mecanizada.

\title{
SUMMARY: EVALUATION OF PHYSICAL PROPERTIES AND SOIL CARBON AND NITROGEN STOCKS AS AFFECTED BY BURNING OR GREENTRASH MANAGEMENT OF SUGARCANE
}

\begin{abstract}
Brazil is the world's largest sugarcane producer, so changes in sugarcane management in Brazil can affect the environment to a great extent. During almost one century, studies were carried out in cropping systems involving pre-harvest burning of aerial sugarcane residues. Nowadays the green trash management of sugarcane residues has become a common practice, although the effects are still poorly documented. The objective of this work was to compare topsoil carbon and nitrogen stocks, aggregation and bulk density in Brazilian sugarcane plantations where aerial residues were either burned (Cq) or left on the soil surface (Sq) after harvest. The study was carried out in three plantations, one on a clayey soil (Latossolo Vermelho, LVdf, i.e. Typic Hapludox) and two on sandy soils (Argissolo Vermelho-Amarelo, PVAd, i.e. Typic Hapludult, and Neossolo Quartzarênico, RQo, i.e. Quartzpsamment). On each plantation, the experimental design included six replications per treatment. After three crops, the accumulated aerial residue biomass in

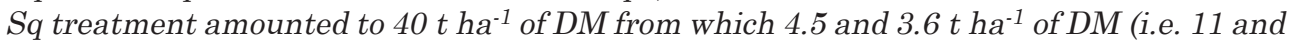
$9 \%)$ were still present at the soil surface in $L V d f$ and RQo, respectively. This represented 1.60 and $1.35 t \mathrm{ha}^{-1}$ of $C$ and 0.022 and $0.021 \mathrm{tha}^{-1}$ of $\mathrm{N}$, respectively. As a result, soil

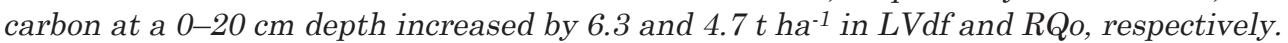
Over the three-year period, the rate of carbon sequestration in the litter and topsoil in the Sq treatment was 2.63 and $2.02 t \mathrm{ha}^{-1} \mathrm{yr}^{-1}$ in $L V d f$ and RQo, respectively. Topsoil content of stable macroaggregates was also higher with $S q$ than with Cq: $814 \mathrm{vs} .693 \mathrm{~g} \mathrm{~kg}^{-1}$ in $L V d f$, and $516 \mathrm{Vs}, 420 \mathrm{~g} \mathrm{~kg}^{-1}$ in RQo, respectively. On the other hand, Sq caused topsoil compaction (PVAd and RQo) due to the mechanized harvest system. In the Brazilian soils under study, green trash management of sugarcane residues improved the topsoil properties and promoted carbon and nitrogen sequestration in the litter and topsoil.
\end{abstract}

Index terms: aggregate stability, burning, mechanized harvest, soil cover.

\section{INTRODUÇÃO}

Em vários países que cultivam a cana-de-açúcar, é comum queimar o canavial antes de realizar a colheita, pois a queima da densa biomassa foliar (palhada) torna mais fácil o corte manual dos colmos. Porém, a queimada provoca vários problemas ambientais, como a liberação de monóxido de $\mathrm{C}(\mathrm{CO})$ e outros gases poluentes na atmosfera, a deposição de cinzas em áreas urbanas e a exposição do solo.

Objetivando amenizar esses problemas, desenvolveram-se máquinas que realizam a colheita sem a necessidade de queimar o canavial. Assim, a palhada que seria queimada e transformada em gases e cinzas passa a cobrir o solo, protegendo-o contra intempéries, melhorando suas condições de conservação. No processo de decomposição, parte da palhada é incorporada ao solo, fazendo com que funcione como um compartimento seqüestrador de $\mathrm{C}$ atmosférico, uma vez que a palhada foi produzida no processo fotossintético de assimilação de $\mathrm{CO}_{2}$ do ar.

Em pesquisas de manejo de resíduos vegetais de colheita, os atributos do solo mais freqüentemente avaliados são o teor de C, usado para calcular a concentração da matéria orgânica do solo (MOS), sabidamente porque ela melhora suas condições químicas, físicas e biológicas (Six et al., 2004); e a estabilidade dos agregados, pois uma estruturação adequada favorece a fertilidade do solo, aumenta seu potencial produtivo e diminui a erodibilidade, sendo fator-chave para moderar o seqüestro de $\mathrm{C}$ no solo (Bronick \& Lal, 2005). O indicador da estrutura do solo é a estabilidade de agregados (Six et al., 2000).

Alguns trabalhos confirmaram que a supressão da queima com manutenção da palhada sobre o solo resultou em maior concentração da MOS, conforme relatado por Wood (1991), Blair (2000), e Noble et al. (2003) na Austrália; Dominy et al. (2002) e Graham 
et al. (2002b) na África do Sul, e Villegas (1998) em Cuba. Estudos realizados no Brasil mostraram que esses efeitos ocorreram em solo muito argiloso (Orlando Filho et al., 1998) e de textura média (Souza et al., 2005), mas não em solo muito arenoso (Ball-Coelho et al., 1993). Aumentos na concentração de macroagregados estáveis em água, devido à supressão da queima do canavial, foram registrados por Ceddia et al. (1999), Graham et al. (2002b) e Souza et al. (2005). Outros estudos encontraram correlação positiva entre concentrações da MOS e estabilidade de macroagregados (Cerri et al., 1991; Blair, 2000; Graham et al., 2002a).

Adversamente aos efeitos benéficos, alguns trabalhos demonstraram que o uso de máquinas na colheita da cana-de-açúcar sem a queima ocasionou compactação do solo (Wood, 1991; Villegas et al., 1998; Ceddia et al., 1999; Braunack \& Peatey, 1999; Souza et al., 2005). A compactação pode trazer conseqüências negativas na agregação e porosidade, prejudicando a infiltração e retenção de água do solo (Wood, 1991; Ball-Coelho et al., 1993; Ceddia et al., 1999). Porém, uma forte estabilidade estrutural associada à cobertura com resíduos vegetais de colheita podem minimizar esse problema, diminuindo o escorrimento superficial (Vieira \& Muzilli, 1984; Shukla et al., 2003; Lado et al., 2004).

O objetivo do trabalho foi conhecer os efeitos da colheita mecanizada sem a queima do canavial sobre os teores da MOS e nas propriedades físicas estabilidade de agregados e densidade do solo, comparados ao método de colheita manual com a queima do canavial.

\section{MATERIAIS E MÉTODOS}

\section{Condições experimentais}

Experimentos com cana-de-açúcar (Saccharum officinarum L.) foram realizados na região nordeste do Estado de São Paulo, especificamente em três municípios: Pradópolis (Usina São Martinho): latitude $21^{\circ} 22^{\prime}$ ' S e longitude $48^{\circ} 03^{\prime}$ 'W; Matão (Usina Santa Luiza): latitude $21^{\circ} 36^{\prime} \mathrm{S}$ e $48^{\circ} 22^{\prime}$ 'longitude W; e Serrana (Usina da Pedra): latitude $21^{\circ} 12^{\prime} \mathrm{S}$ e $47^{\circ} 35^{\prime}$ 'longitude W. As precipitações médias anuais dos três municípios são, respectivamente, 1.560, 1.469 e $1.549 \mathrm{~mm}$, e a temperatura média anual é $22,9^{\circ} \mathrm{C}$ nos três municípios (estações climáticas locais).

Os solos de Pradópolis, Matão e Serrana, nas classificações da Embrapa (1999) e US Soil Taxonomy (Estados Unidos, 1975), são, respectivamente: Latossolo Vermelho distroférrico (LVdf) e Typic Hapludox; Argissolo Vermelho-Amarelo distrófico (PVAd) e Typic Hapludult; e Neossolo Quartzarênico órtico (RQo) e Typic Quartzipsamment. Os grupos e as formações geológicas são: LVdf - grupo São Bento e formação Serra Geral; PVAd - grupo Bauru e formação
Adamantina e RQo - sedimentos continentais indiferenciados. O relevo local é ondulado, com declividade máxima de $3 \mathrm{~cm} \mathrm{~m}^{-1}$ (Oliveira \& Prado, 1987). As texturas médias até a profundidade de $40 \mathrm{~cm}$ no LVdf, PVAd e RQo são, respectivamente, para as frações argila, silte e areia: 682, 200 e $90 \mathrm{~g} \mathrm{~kg}^{-1} ; 141$, 50 e $45 \mathrm{~g} \mathrm{~kg}^{-1}$ e 177, 750 e $865 \mathrm{~g} \mathrm{~kg}^{-1}$.

Até a instalação do experimento, os três locais foram cultivados com cana-de-açúcar sob queima no mínimo há cinco décadas. As variedades plantadas foram: SP 80-185 no LVdf; SP 79-2233 no PVAd, e RB 78-5148 no RQo. Preparou-se o solo no sistema convencional, consistindo basicamente das seguintes operações: grade pesada por duas ou três vezes para eliminação da soqueira anterior; grade intermediária objetivando destorroamento do solo; subsolagem seguida de grade leve para nivelamento do solo. Utilizaram-se culturas em rotação com os seguintes manejos: amendoim (Arachis hypogea) com sulcação e plantio da cana em áreas recém-colhidas no LVdf; crotalária (Crotalaria juncea) com sulcação para plantio da cana após erradicação e secagem das plantas no PVAd; e mucuna preta (Stylozobium aterrimum), dessecada e incorporada ao solo com grade antes do plantio da cana no RQo.

Adubou-se com N, $\mathrm{Pe} \mathrm{K}\left(\mathrm{N}, \mathrm{P}_{2} \mathrm{O}_{5}\right.$ e $\left.\mathrm{K}_{2} \mathrm{O}\right)$ nas doses 25,125 e $125 \mathrm{~kg} \mathrm{ha}^{-1}$ o sulco de plantio, e com 85, 50, $100 \mathrm{~kg} \mathrm{ha}^{-1}$ ano $^{-1} \mathrm{em}$ cobertura a partir da primeira colheita. As fontes desses nutrientes foram nitrato de amônio, superfosfato simples e cloreto de potássio, respectivamente. No tratamento com queima da palhada (Cq), os fertilizantes foram distribuídos sobre solo e, no tratamento sem queima da palhada (Sq), foram distribuídos sobre a palhada.

O experimento de campo foi estabelecido em blocos ao acaso, com seis repetições e dois tratamentos: colheita manual em solo Cq e colheita mecanizada em solo Sq. As parcelas tinham largura de 29,4 m (21 linhas de plantio com espaçamento de 1,4 m entre as linhas) e comprimento de $70 \mathrm{~m}$, totalizando $2.058 \mathrm{~m}^{2}(0,206 \mathrm{ha})$ por parcela. Apenas as nove linhas e os $50 \mathrm{~m}$ de comprimento centrais foram considerados parcela útil nas amostragens (Figura 1).

No tratamento de solo Cq, foram feitos o corte e a colheita da cana no máximo uma semana após a queima. Nesse tratamento a cana cortada é amontoada e, usando-se trator equipado com grua, colocada em equipamento (transbordo) tracionado por trator agrícola para transporte primário (até o carreador). No tratamento de solo Sq, utilizou-se uma máquina que corta a cana, pica e a distribui sobre o transbordo, que trafega paralelamente. Esta máquina colhedora lança os resíduos leves sobre o solo, formando o colchão de palhada.

O transbordo roda com pneu de alta flotação (capacidade de deformação) e baixa pressão, características que reduzem a pressão sobre o solo, diminuindo o risco de compactação. Pelo mesmo motivo, a máquina colhedora roda sobre esteiras. 
Quando é atingida a capacidade de carga (em torno de 4 t) do transbordo, este é deslocado até o carreador e sua carga é transferida para carrocerias triplas (treminhões ou rodotrens). Estes treminhões trafegam em carreadores principais e rodovias, mas nunca em áreas de plantio. Além disso, a colheita é sempre feita quando é baixa a umidade do solo.

\section{Amostragem da palhada}

As amostragens foram realizadas uma semana antes da quarta colheita da cana. Coletaram-se cinco amostras retangulares, com dimensões de $0,5 \mathrm{~m} \mathrm{x}$ 0,7 m (Figura 1). Adotou-se o comprimento de 0,7 m para amostrar justamente metade da largura da entrelinha $(1,4 \mathrm{~m})$, pois considerou-se uniforme a distribuição da palhada sobre o solo.

\section{Amostragem do solo e preparo das amostras para análises}

Amostrou-se o solo na mesma época de amostragem da palhada. Utilizou-se trado holandês para coleta das amostras nas profundidades $0-5,5-10,10-20 \mathrm{e}$ 20-40 cm. Foram coletadas seis subamostras (Figura 1), que foram misturadas de modo a fazer uma amostra composta em cada parcela e profundidade. Após secagem ao ar, até atingirem massa constante, as amostras foram cuidadosamente destorroadas utilizando-se martelo de borracha. Em seguida, fez-se o peneiramento em peneira com abertura de $2,0 \mathrm{~mm}$. Este foi o procedimento de preparo da terra fina seca ao ar (TFSA).

\section{Determinação dos teores e estoques de carbono e nitrogênio totais}

Uma porção de TFSA foi moída com bastão de porcelana e passada em peneira com abertura de

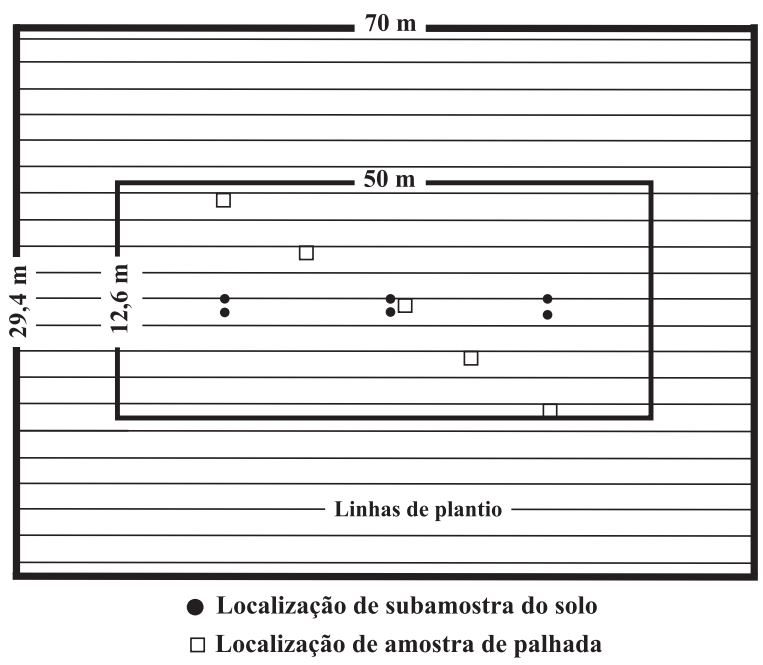

Figura 1. Representação da parcela de amostragem e localização das subamostras de solo e amostras de palhada. As linhas horizontais representam as linhas de plantio de cana-de-açúcar.
0,1 $\mathrm{mm}$ para a determinação do teor de $\mathrm{C}$ e $\mathrm{N}$ total por combustão a seco (Nelson \& Sommers, 1986) em aparelho Leco CN 2000. Calcularam-se os estoques de $\mathrm{C}$ e $\mathrm{N}$ por dois métodos: em espessura de camada pré-estabelecida (mesma espessura entre tratamentos) e em "massa equivalente de solo" (Ellert \& Bettany, 1995). Este segundo método estabelece que se deve aumentar a espessura da(s) camadas(s) menos densa(s), de modo a igualar sua massa de solo à massa de solo da camada mais densa. Para ambos os métodos, usou-se a fórmula: [Teor de $\mathrm{C}\left(\mathrm{g} \mathrm{kg}^{-1}\right)$ x E x D], em que $\mathrm{E}=$ espessura da camada $(\mathrm{dm})$ e $\mathrm{D}=$ densidade do solo $\left(\mathrm{kg} \mathrm{dm}^{-3}\right)$ na camada.

\section{Determinação da estabilidade estrutural do solo}

Procedeu-se à determinação via úmida, método adaptado de Kemper \& Rosenau (1986). Quatro gramas de TFSA foram colocados sobre peneira com abertura de 0,2 $\mathrm{mm}$ e, em seguida, imergidos lentamente em copo contendo $100 \mathrm{~mL}$ de água desmineralizada. A terra foi mantida imersa durante 30 min em temperatura ambiente. A tamisagem foi realizada em movimentos verticais alternados (35 ciclos $\mathrm{min}^{-1}$ ) numa amplitude de $7 \mathrm{~cm}$ durante $6 \mathrm{~min}$. Feita a tamisagem, restou na peneira uma fração constituída de macroagregados estáveis em água $(2,0 \mathrm{~mm}<\mathrm{MA}<0,2 \mathrm{~mm})$ ainda associada com areia grossa $(2,0 \mathrm{~mm}<\mathrm{AG}<0,2 \mathrm{~mm})$. Fez-se a secagem desta fração até massa constante e determinou-se sua massa seca. Fez-se a dispersão desta fração por hidróxido de sódio $0,05 \mathrm{~mol} \mathrm{~L}^{-1}$ e novamente peneirouse em malha de 0,2 mm. Os macroagregados (MA), agora dispersados, passaram pela peneira sobre a qual restou a AG. A massa de MA foi calculada subtraindo a massa de $\mathrm{AG}$, retida na peneira, da totalidade da massa da fração entre 2,0 e $0,2 \mathrm{~mm}$. Na parte que passou pela peneira $(<0,2 \mathrm{~mm})$, determinou-se a fração dos microagregados estáveis em água (MI $<0,02 \mathrm{~mm}$ ) pelo método da pipeta (Robinson, 1967). A massa de mesoagregados estáveis em água $(0,2 \mathrm{~mm}$ $<\mathrm{ME}<0,02 \mathrm{~mm}$ ) foi determinada subtraindo-se a soma das massas das demais frações (AG, MA e MI) da massa total da amostra (4 g). A análise foi repetida quatro vezes, utilizando-se nova amostra composta pelas seis amostras originais de cada tratamento, apenas para a camada $0-5 \mathrm{~cm}$.

As classes de agregados foram expressas em proporção de terra total (até $2,0 \mathrm{~mm}$ ) dispersa e em proporção de terra livre de $\mathrm{AG}(<0,2 \mathrm{~mm})$ dispersa. Assim, adotaram-se as notações MA, ME e MI, e MA', ME' e MI', respectivamente para macro, meso e microagregados em proporção de terra total e de terra livre de AG, em que MA' = 1.000 MA/(1.000-AG); ME' $=1.000 \mathrm{ME} /(1.000-\mathrm{AG})$ e $\mathrm{MI}^{\prime}=1.000 \mathrm{MI} /(1000-\mathrm{AG})$.

\section{Determinação da densidade do solo}

Coletaram-se amostras indeformadas (duas em cada parcela) utilizando cilindro de aço com volume de $0,098 \mathrm{dm}^{3}$ (diâmetro $=5 \mathrm{~cm}$ e altura $=5 \mathrm{~cm}$ ) 
acoplado a trado tipo "Uhland", nas profundidades 0$10,10-20$ e $20-40 \mathrm{~cm}$. Posicionaram-se os dois pontos de amostragem a $20 \mathrm{~cm}$ daqueles centrais na amostragem do solo. $\mathrm{O}$ solo do cilindro foi seco a $110^{\circ} \mathrm{C}$ até massa constante. $\mathrm{O}$ cálculo da densidade do solo se deu pela divisão: massa de solo seco/volume do cilindro.

\section{Análise estatística}

Utilizou-se o software SAS (SAS, 1990) para investigar se houve diferença entre tratamentos, aplicando-se análise de variâncias pelo procedimento GLM. As médias dos tratamentos foram comparadas por meio de teste t pareado, a $5 \%$.

\section{RESULTADOS E DISCUSSÃO}

\section{Matéria orgânica}

A quantidade total de palhada adicionada em três colheitas foi 40 e $39 \mathrm{t} \mathrm{ha}^{-1}$ de matéria seca no Latossolo Vermelho (LVdf) e no Neossolo Quartzarênico (RQo), respectivamente; o que corresponde à taxa de entrada de 13,3 $\mathrm{t} \mathrm{ha}^{-1}$ ano $^{-1}$ nos dois solos. Souza et al. (2005) mediram 12 t ha $^{-1}$ ano $^{-1}$ como adição de palhada. Não houve avaliação da palhada no Argissolo VermelhoAmarelo (PVAd). A avaliação feita quatro anos após a instalação do experimento, antes da quarta colheita, mostrou que houve formações de camadas orgânicas sobre o solo com vários graus de decomposição. E a acumulação desses resíduos foi $4,5 \mathrm{t} \mathrm{ha}^{-1}\left(1,60 \mathrm{t} \mathrm{ha}^{-1}\right.$ em C e 0,022 $\mathrm{t} \mathrm{ha}^{-1}$ em N) no LVdf e 3,6 t ha-1 $\left(1,35 \mathrm{t} \mathrm{ha}^{-1}\right.$ em C e $\left.0,021 \mathrm{t} \mathrm{ha}^{-1} \mathrm{em} \mathrm{N}\right)$ no RQo. Dessa forma, a decomposição do total adicionado foi de $89 \%$ no LVdf e $91 \%$ no RQo.

As concentrações de $\mathrm{C}$ variaram entre $15,4 \mathrm{e}$ $22,7 \mathrm{~g} \mathrm{~kg}^{-1}$ no LVdf, e entre 4,9 e 9,6 $\mathrm{g} \mathrm{kg}^{-1}$ considerando conjuntamente o PVAd e o RQo. Numa mesma camada, o LVdf apresentou, no mínimo, duas vezes o teor medido no PVAd ou RQo, independente do tratamento. As concentrações de $\mathrm{N}$ variaram entre 1,04 e $1,45 \mathrm{~g} \mathrm{~kg}^{-1}$ no LVdf, e entre 0,19 e $0,71 \mathrm{~g} \mathrm{~kg}^{-1}$ considerando conjuntamente o PVAd e o RQo. Comparativamente ao manejo com queima há várias décadas $(\mathrm{Cq})$, houve elevação significativa no teor de $\mathrm{C}$ (0-5 cm) de 18,1 para $22,7 \mathrm{~g} \mathrm{~kg}^{-1}$ no LVdf e de 6,7 para $9,6 \mathrm{~g} \mathrm{~kg}^{-1}$ no RQo. Esse efeito ocorreu também na concentração de $\mathrm{N}$ do RQo, resultando em alteração de 0,22 para $0,40 \mathrm{~g} \mathrm{~kg}^{-1}$. Mas não houve aumentos significativos das concentrações no PVAd (Quadro 1).

As quantidades estocadas de $\mathrm{C}$ e $\mathrm{N}$ foram também amplamente distintas entre solos. Considerando a camada $0-20 \mathrm{~cm}$, os estoques de $\mathrm{C}$ variaram entre 47,9 e $54,2 \mathrm{t} \mathrm{ha}^{-1}$ no LVdf, e entre 20,9 e $28,5 \mathrm{t} \mathrm{ha}^{-1}$ considerando conjuntamente o PVAd e o RQo. E os

Quadro 1. Concentração e estoque de carbono e nitrogênio dos solos sob os manejos com queima (Cq) e sem queima (Sq) de canavial

\begin{tabular}{|c|c|c|c|c|c|c|c|c|}
\hline \multirow{3}{*}{ Camada de solo } & \multicolumn{4}{|c|}{ Carbono } & \multicolumn{4}{|c|}{ Nitrogênio } \\
\hline & \multicolumn{2}{|c|}{ Concentração } & \multicolumn{2}{|c|}{ Estoque } & \multicolumn{2}{|c|}{ Concentração } & \multicolumn{2}{|c|}{ Estoque } \\
\hline & $\mathrm{Cq}$ & Sq & $\mathbf{C q}$ & $\mathrm{Sq}$ & $\mathrm{Cq}$ & $\mathrm{Sq}$ & $\mathrm{Cq}$ & $\mathrm{Sq}$ \\
\hline \multirow[t]{2}{*}{$\mathrm{cm}$} & 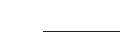 & $g^{-1}$ & $-\mathrm{t}$ & - & 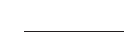 & 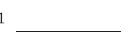 & $-\mathrm{th}$ & 1 \\
\hline & \multicolumn{6}{|c|}{ Latossolo Vermelho distroférrico - LVdf } & & \\
\hline $0-5$ & $18,1 \mathrm{Ba}$ & $22,7 \mathrm{Aa}$ & $11,8 \mathrm{~B}$ & $14,9 \mathrm{~A}$ & $1,24 \mathrm{Aa}$ & $1,39 \mathrm{Aa}$ & $0,80 \mathrm{~A}$ & $0,91 \mathrm{~A}$ \\
\hline $5-10$ & $19,2 \mathrm{Aa}$ & $22,0 \mathrm{Aa}$ & $12,5 \mathrm{~A}$ & $13,1 \mathrm{~A}$ & $1,31 \mathrm{Aa}$ & $1,45 \mathrm{Aa}$ & $0,85 \mathrm{~A}$ & $0,95 \mathrm{~A}$ \\
\hline $10-20$ & $18,1 \mathrm{Aa}$ & $19,1 \mathrm{Aa}$ & $23,6 \mathrm{~A}$ & $26,2 \mathrm{~A}$ & $1,32 \mathrm{Aa}$ & $1,37 \mathrm{Aa}$ & $1,72 \mathrm{~A}$ & $1,88 \mathrm{~A}$ \\
\hline $20-40$ & $15,4 \mathrm{Bb}$ & $18,0 \mathrm{Aa}$ & $38,1 \mathrm{~B}$ & $45,3 \mathrm{~A}$ & $1,04 \mathrm{Aa}$ & $1,21 \mathrm{Aa}$ & $2,60 \mathrm{~A}$ & $3,05 \mathrm{~A}$ \\
\hline \multirow[t]{2}{*}{$0-20$} & & & $47,9 \mathrm{~B}$ & $54,2 \mathrm{~A}$ & & & $3,37 \mathrm{~A}$ & $3,74 \mathrm{~A}$ \\
\hline & \multicolumn{8}{|c|}{ Argissolo Vermelho-Amarelo distrófico - PVAd } \\
\hline $0-5$ & $8,4 \mathrm{Ab}$ & $9,6 \mathrm{Ab}$ & $6,4 \mathrm{~A}$ & $7,6 \mathrm{~A}$ & $0,56 \mathrm{Abc}$ & $0,64 \mathrm{Ab}$ & $0,42 \mathrm{~A}$ & $0,53 \mathrm{~A}$ \\
\hline $5-10$ & $7,6 \mathrm{Ab}$ & $7,9 \mathrm{Ab}$ & $5,8 \mathrm{~A}$ & $6,6 \mathrm{~A}$ & $0,45 \mathrm{Abc}$ & $0,71 \mathrm{Ab}$ & $0,34 \mathrm{~A}$ & $0,58 \mathrm{~A}$ \\
\hline $10-20$ & $7,1 \mathrm{Ab}$ & $8,3 \mathrm{Ab}$ & $11,8 \mathrm{~A}$ & $14,3 \mathrm{~A}$ & $0,51 \mathrm{Abc}$ & $0,62 \mathrm{Ab}$ & $0,85 \mathrm{~A}$ & $1,06 \mathrm{~A}$ \\
\hline $20-40$ & $6,0 \mathrm{Ac}$ & $6,9 \mathrm{Ac}$ & $19,7 \mathrm{~A}$ & $23,0 \mathrm{~A}$ & $0,47 \mathrm{Ab}$ & $0,57 \mathrm{Ab}$ & $1,53 \mathrm{~A}$ & $1,89 \mathrm{~A}$ \\
\hline \multirow[t]{2}{*}{$0-20$} & & & $24,0 \mathrm{~A}$ & $28,5 \mathrm{~A}$ & & & $1,61 \mathrm{~A}$ & $2,17 \mathrm{~A}$ \\
\hline & \multicolumn{8}{|c|}{ Neossolo Quartzarênico órtico - RQo } \\
\hline $0-5$ & $6,7 \mathrm{Bc}$ & $9,6 \mathrm{Ab}$ & $4,8 \mathrm{~B}$ & $7,6 \mathrm{~A}$ & $0,31 \mathrm{Bc}$ & $0,50 \mathrm{Abc}$ & $0,22 \mathrm{~B}$ & $0,40 \mathrm{~A}$ \\
\hline $5-10$ & $7,4 \mathrm{Ab}$ & $7,4 \mathrm{Ab}$ & $5,3 \mathrm{~A}$ & $5,7 \mathrm{~A}$ & $0,27 \mathrm{Ac}$ & $0,35 \mathrm{Ac}$ & $0,19 \mathrm{~A}$ & $0,26 \mathrm{~A}$ \\
\hline $10-20$ & $6,9 \mathrm{Ab}$ & $7,3 \mathrm{Ab}$ & $10,8 \mathrm{~A}$ & $12,3 \mathrm{~A}$ & $0,29 \mathrm{Ac}$ & $0,37 \mathrm{Abc}$ & $0,46 \mathrm{~A}$ & $0,62 \mathrm{~A}$ \\
\hline $20-40$ & $4,9 \mathrm{Ac}$ & $5,0 \mathrm{Ac}$ & $16,0 \mathrm{~A}$ & $16,1 \mathrm{~A}$ & $0,19 \mathrm{Ac}$ & $0,21 \mathrm{Ac}$ & $0,60 \mathrm{~A}$ & $0,67 \mathrm{~A}$ \\
\hline $0-20$ & & & $20,9 \mathrm{~B}$ & $25,6 \mathrm{~A}$ & & & $0,87 \mathrm{~B}$ & $1,28 \mathrm{~A}$ \\
\hline
\end{tabular}

Médias seguidas de mesmo algarismo não diferem entre si pelo teste t pareado. As letras maiúsculas comparam os tratamentos com queima $(\mathrm{Cq})$ e sem queima $(\mathrm{Sq})$ na mesma linha, considerando o mesmo elemento e mesma variável. As letras minúsculas comparam as camadas na mesma coluna, considerando o mesmo solo. 
estoques de $\mathrm{N}$ variaram entre $3,37 \mathrm{e} 3,74 \mathrm{t}$ ha $\mathrm{a}^{-1}$ e entre 0,87 e 2,17 t ha-1, respectivamente. Nos três solos, maiores concentrações e estoques de $\mathrm{C}$ e $\mathrm{N}$ ocorreram em solos Sq, sobretudo na camada $0-5 \mathrm{~cm}$, onde apareceram diferenças significativas em relação a solos Cq (Quadro 1).

Dessa forma, a supressão da queima resultou em aumentos no estoque de $\mathrm{C}(0-20 \mathrm{~cm})$ de $6,3 \mathrm{t} \mathrm{ha}^{-1}$ no LVdf e 4,7 t ha-1 no RQo. Quanto ao N, o aumento ocorreu apenas para o RQo e foi de 0,41 $\mathrm{t} \mathrm{ha}^{-1}$. Considerando o efeito do manejo Sq por três anos, esses valores correspondem a taxas de seqüestro de $\mathrm{C}$ (SeqC) de 2,1 t ha-1 ano $^{-1}$ no LVdf e 1,57 t ha-1 ano-1 no RQo, e taxa de seqüestro de N (SeqN) de 0,14 $\mathrm{t} \mathrm{ha}^{-1} \mathrm{ano}^{-1}$ no RQo. Se as taxas de SeqC nos resíduos acumulados sobre o solo foram 0,53 e $0,45 \mathrm{t} \mathrm{ha}^{-1} \mathrm{ano}^{-1}$, a taxa de SeqC no compartimento cobertura + solo $(0-20 \mathrm{~cm})$ foi de 2,63 e 2,02 $\mathrm{t} \mathrm{ha}^{-1}$ ano $^{-1}$ no LVdf e RQo, respectivamente. Sendo 0,007 t ha-1 ano-1 a taxa de SeqN nos resíduos acumulados, a taxa de SeqN no compartimento cobertura + solo $(0-20 \mathrm{~cm})$ foi de $0,147 \mathrm{t} \mathrm{ha}^{-1} \mathrm{ano}^{-1} \mathrm{no}$ RQo.

Estimando que $20 \%$ dos 5,6 Mha cultivados com cana-de-açúcar no Brasil (Indicadores, 2005) são colhidos sem queima anualmente e considerando que os solos argiloso (LVdf) e arenoso (RQo) fazem 2,33 $\mathrm{t} \mathrm{ha}^{-1} \mathrm{ano}^{-1}$ como taxa média de SeqC na cobertura mais a camada $0-20 \mathrm{~cm}$ de solo, a estimativa do potencial de SeqC devido ao manejo sem queima de canavial no País é $2,61 \mathrm{Tg}^{\mathrm{ano}}{ }^{-1}(1 \mathrm{Tg}=1 \mathrm{Mt})$, potencial equivalente a $9,57 \mathrm{Tg}$ ano-1 em $\mathrm{CO}_{2}$.

No Brasil, resultados experimentais comparando os manejos Cq e Sq mostraram que ocorreu aumento da MOS em solo muito argiloso (Orlando Filho et al., 1998) e de textura média (Souza et al., 2005), mas esse efeito não ocorreu em solo muito arenoso (BallCoelho et al., 1993). Wood (1991) mediu aumento da MOS de sete solos australianos a partir do segundo ano sem queima do canavial. Porém, Blair (2000) mediu a diminuição no teor de $\mathrm{C}$ após quatro anos de supressão da queima do canavial em solo australiano semelhante ao argissolo deste estudo. Mas o inverso ocorreu quanto ao C lábil.

Estudos mais recentes mostram que manejos de longo período influenciam substancialmente o teor de MOS. Noble et al. (2003) mediram aumento no teor de $\mathrm{C}$ em solo australiano $(0-2 \mathrm{~cm})$ de $14,7(\mathrm{Cq})$ para $30,0 \mathrm{~g} \mathrm{~kg}^{-1}$ (Sq) depois de sete anos. O seqüestro de C decorrente do manejo sem queima foi $4,73 \mathrm{t} \mathrm{ha}^{-1}$ (0-5 cm), ou 0,67 t ha ${ }^{-1}$ ano $^{-1}$, cerca de $50 \%$ maior do que no LVdf deste estudo. Efeito semelhante foi encontrado na África do Sul em experimento com mais de quinze anos (Dominy et al., 2002); o teor de C que era cerca de $30 \mathrm{~g} \mathrm{~kg}^{-1}(\mathrm{Cq})$ passou para cerca de $45 \mathrm{~g} \mathrm{~kg}^{-1}(\mathrm{Sq})$. Esse valores são surpreendentes considerando-se o baixo teor de argila deste solo (próximo de $200 \mathrm{~g} \mathrm{~kg}^{-1}$ ). Aqui, mais uma vez, foi verificado que as formas mais lábeis do $\mathrm{C}$ (extraível em $\mathrm{K}_{2} \mathrm{SO}_{4}$ ) aumentaram em maior proporção do que o $\mathrm{C}$ total.
O estudo de maior período de comparação entre manejos com e sem queima encontrado foi publicado por Graham et al. (2002b). Trata-se de um experimento instalado em 1939, na África do Sul, e que na ocasião da amostragem contava com 59 anos. $\mathrm{O}$ teor de $\mathrm{C}$ aumentou nas camadas amostradas até $10 \mathrm{~cm}(0-2,5 ; 2,5-5,0$ e 5-10 cm) e o maior efeito se deu na primeira camada, com aumento de $43 \mathrm{~g} \mathrm{~kg}^{-1}$ (Cq) para $55 \mathrm{~g} \mathrm{~kg}^{-1}(\mathrm{Sq})$. Esses valores referem-se a tratamentos com fertilização. Em tratamentos não fertilizados, também ocorreu efeito significativo entre os manejos, mas os valores dentro e entre os manejos foram significativamente menores comparados aos que receberam fertilização. Atribuiu-se maior concentração de $\mathrm{C}$ em tratamentos com aplicação de adubos devido a maior produção de cana e, consequentemente, à deposição de maior quantidade de palhada. Em termos de estoques de $\mathrm{C}$ deste solo, com teor de argila em torno de $580 \mathrm{~g} \mathrm{~kg}^{-1}$, foram apresentados apenas os valores referentes à camada 0-30 cm, que foi cerca de $137 \mathrm{t} \mathrm{ha}^{-1}$ para ambos os manejos. Relata-se que na camada $0-10 \mathrm{~cm}$ o estoque foi significativamente maior no manejo sem queima, mas os valores não foram apresentados.

Este estudo reafirma variações mais sensíveis nas frações mais lábeis da MOS quando comparadas às do teor total. Carbono e $\mathrm{N}$ microbianos, $\mathrm{C}$ extraível em $\mathrm{K}_{2} \mathrm{SO}_{4}$ e fração leve aumentaram em maiores proporções que o teor total da MOS. Os aumentos também ocorreram nas camadas mais profundas (10 20 e $20-30 \mathrm{~cm}$ ), e as possíveis causas são a percolação dos componentes lábeis e a redistribuição de partículas da palhada pela fauna do solo (minhocas, por exemplo). Também é aventada a hipótese de maior concentração e renovação de raízes superficiais nas entrelinhas, cobertas pela palhada. Assim haveria maior deposição de material leve. Entende-se que é de grande importância o estudo dessas frações da MOS para as situações do Brasil.

O manejo de plantio direto de culturas anuais, que se assemelha a Sq quanto à manutenção de resíduos vegetais de colheita sobre o solo, também concorre em SeqC quando comparado ao manejo convencional com queima dos resíduos. Utilizando resultados de Sá et al. (2001) e Castro Filho et al. (2002) foram calculadas taxas de SeqC em Latossolo Argiloso (0-5 cm) do Paraná $\left(\mathrm{d}=1,2 \mathrm{~kg} \mathrm{dm}^{-3}\right)$, sob plantio direto há mais de vinte anos, respectivamente de 0,69 e 0,31 $\mathrm{t} \mathrm{ha}^{-1}$ ano $^{-1}$; e $0,67 \mathrm{t} \mathrm{ha}^{-1} \mathrm{ano}^{-1}$ na camada $0-20 \mathrm{~cm}$, após quinze anos de cultivo no Distrito Federal (Corazza et al., 1999). Bayer et al. (2000) reportaram taxa de SeqC de $0,86 \mathrm{t} \mathrm{ha}^{-1} \mathrm{ano}^{-1}$ na camada $0-17,5 \mathrm{~cm}$, após nove anos de cultivo em solo de textura média no Rio Grande do Sul.

De fato, o solo é um compartimento com elevado potencial para seqüestrar $\mathrm{CO}_{2}$ atmosférico quando se mantêm os resíduos vegetais de colheita, permitindo acelerar os estoques da MOS (Lal, 1999; Bayer et al., 2000; Feller et al., 2001; Lal, 2004). Neste estudo, os 
aumentos de estoques ocorreram devido ao aumento nas concentrações de $\mathrm{C}$ do solo. Maior densidade de solo, que por vezes ocorreu em Sq, não foi fator determinante do aumento de estoque de $\mathrm{C}$ no solo. Isso foi comprovado pela igualdade estatística entre os métodos de quantificação de estoque: espessura de camada pré-estabelecida e "massa equivalente de solo" (Ellert \& Bettany, 1995).

Os solos aqui estudados são de texturas distintas, e o teor de $\mathrm{C}$ foi maior quanto maior o teor de argila. Em relação às estocagens do LVdf, as capacidades de estocagem de $\mathrm{C}$ e $\mathrm{N}$ foram de 52,6 e 58,0 \% pelo PVAd e 47,2 e 34,2 \% pelo RQo. Essa relação direta entre argila e C já foi bem relatada (Lepsch et al., 1982; Lepsch et al., 1994; Feller et al., 1996). Particularmente, as concentrações de $\mathrm{C}$ de todos os solos deste trabalho estão de acordo com o gráfico de correlação entre C de solos tropicais e sua textura, elaborado por Feller et al. (1996). Neste estudo, ficou claro o efeito sobre a estocagem de $\mathrm{C}$ na camada $0-5 \mathrm{~cm}$ dos solos muito argiloso (LVdf) e muito arenoso (RQo), mas não ficou para o solo de textura intermediária (PVAd).

Observou-se que, no RQo, o teor de C original (Cq) foi de $6,7 \mathrm{~g} \mathrm{~kg}^{-1} \mathrm{e}$, após quatro anos da supressão da queima, o teor passou para $9,6 \mathrm{~g} \mathrm{~kg}^{-1}(\mathrm{Sq}) \mathrm{e}$ ultrapassou o teor do PVAd sob Cq $\left(8,4 \mathrm{~g} \mathrm{~kg}^{-1}\right)$, igualando-se ao teor deste solo sob Sq $\left(9,6 \mathrm{~g} \mathrm{~kg}^{-1}\right)$. Isso demonstrou o elevado potencial do manejo da palhada em elevar a concentração da MOS neste solo arenoso com baixa concentração de $\mathrm{C}$ original, o que pode ser fundamental para melhorar sua estrutura.

As relações $\mathrm{C} / \mathrm{N}$ foram próximas entre $\mathrm{LVdf}$ e PVAd, variando nesses dois solos entre 12,4 e 17,6, enquanto o RQo teve maiores relações, de 19,4 a 29,1. A relação do tratamento $\mathrm{Sq}$ foi maior do que $\mathrm{Cq}$ na camada $0-5 \mathrm{~cm}$ do LVdf. No PVAd e no RQo, $\mathrm{C} / \mathrm{N}$ foi maior em Cq em relação à Sq, na camada $5-10 \mathrm{~cm}$. No LVdf, a alteração decorrente da adição de palhada foi mais pronunciada no teor de C, enquanto em RQo o teor de $\mathrm{N}$ aumentou em maiores proporções. Conseqüentemente, após a deposição da palhada, a relação $\mathrm{C} / \mathrm{N}$ foi significativamente maior no $\mathrm{PVdf}$ $(0-5 \mathrm{~cm})$. Por outro lado, menor C/N em Sq no RQo $(5-10 \mathrm{~cm})$ pode ser devido à alta relação na condição original (Cq) (Figura 2).

A diminuição da relação $\mathrm{C} / \mathrm{N}$ é condicionada pelo consumo da palhada pelos microrganismos do solo, que o liberam na forma de $\mathrm{CO}_{2}$. Esse processo é indicativo da humificação da MOS, e nesse caso há indicação de que a decomposição e humificação se processam mais rapidamente no solo arenoso. Isso é coerente com a característica de maior macroporosidade neste tipo de solo, o que proporciona melhores condições de aeração e atividade da microfauna decompositora. Por outro lado, menor decomposição da palhada no solo argiloso (LVdf) explicaria maior $\mathrm{C} / \mathrm{N}$ na superfície deste solo, onde se concentra a deposição da palhada fresca com alta relação $\mathrm{C} / \mathrm{N}$. A diferença entre as

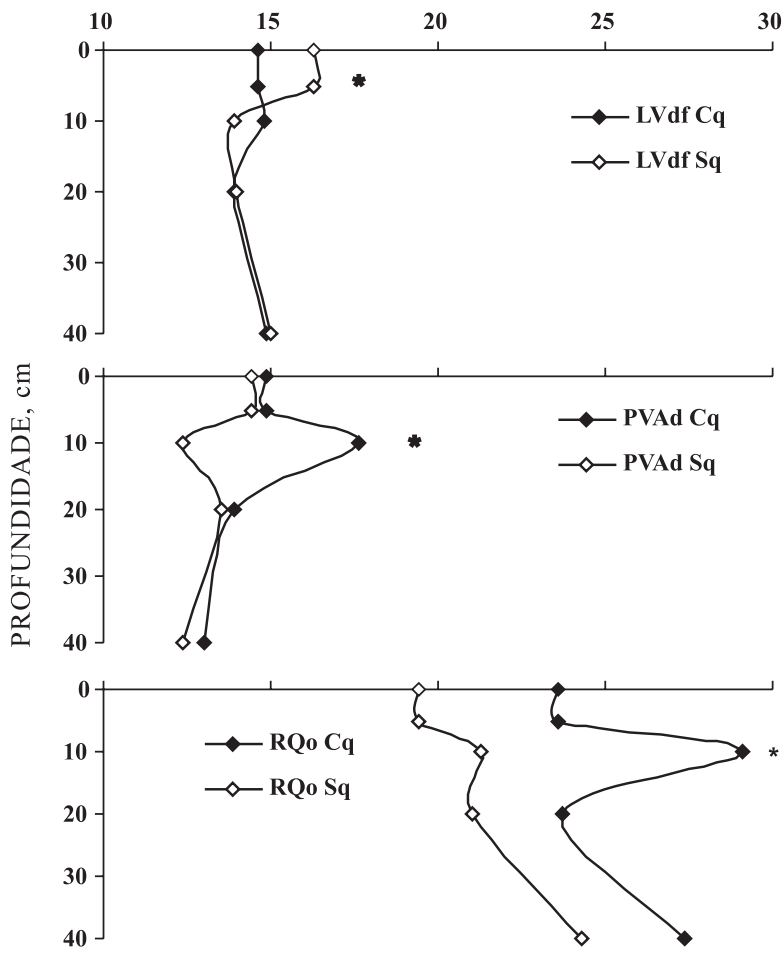

Figura 2. Relação C/N do Latossolo Vermelho distroférrico (LVdf), Argissolo VermelhoAmarelo distrófico (PVAd) e Neossolo Quartzarênico órtico (RQo) sob os manejos com queima (Cq) e sem queima (Sq) de canavial nas diferentes profundidades. * Diferença estatística entre tratamentos na mesma profundidade, de acordo com o teste t pareado.

relações $\mathrm{C} / \mathrm{N}$ dos manejos $\mathrm{Cq}$ e $\mathrm{Sq}$ num mesmo solo indica que a palhada ainda não está bem decomposta. Medições feitas por Oliveira et al. (1999) indicaram diminuição da relação $\mathrm{C} / \mathrm{N}$ da palhada da cana de 97 , logo após o corte, para 68 depois de um ano de deposição.

Porém, os efeitos podem ser influenciados pelo tipo de manejo adotado. Sá et al. (2001) e Graham et al. (2002b) atribuíram a menor relação $\mathrm{C} / \mathrm{N}$ nas camadas superficiais ao suprimento de $\mathrm{N}$ tanto dos resíduos vegetais como dos fertilizantes aplicados.

\section{Estabilidade estrutural}

A concentração de macroagregados estáveis em água livre de areia (MA') foi elevada em LVdf (693$814 \mathrm{~g} \mathrm{~kg}^{-1}$ ) e PVAd (668-717 $\mathrm{g} \mathrm{kg}^{-1}$ ), caracterizando boa estabilidade estrutural dos dois solos. Por outro lado, essa concentração foi menor no RQo (420-516 g kg-1), portanto com menor estabilidade estrutural. Seguindo o mesmo comportamento dos teores da MOS, a estabilidade estrutural $(0-5 \mathrm{~cm})$ foi significativamente maior nos solos sob o manejo sem queima, em relação ao manejo com queima, no LVdf e no RQo (Figura 3).

Correlações positivas entre estabilidade e textura de solos sob cana de açúcar foram registradas por Cerri 

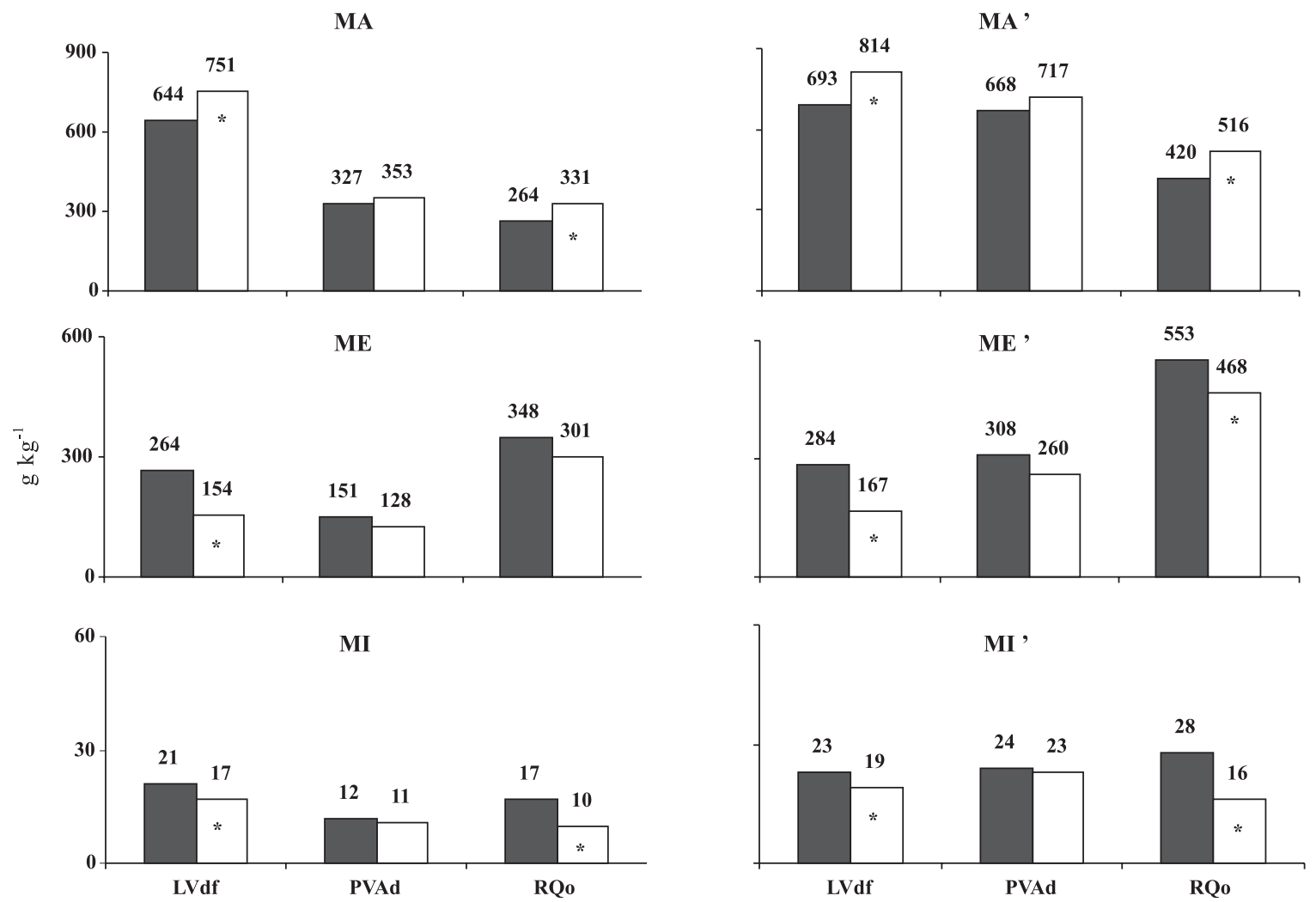

Figura 3. Concentração de agregados estáveis em água do Latossolo Vermelho distroférrico (LVdf), Argissolo Vermelho-Amarelo distrófico (PVAd) e Neossolo Quartzarênico órtico (RQo) sob os manejos com queima (Cq) e sem queima (Sq) de canavial. As notações MA, ME, MI e MA', ME', MI' significam macroagregados, mesoagregados e microagregados em proporção ao solo total e em proporção ao solo livre de areia, respectivamente. * Diferença estatística entre tratamentos no mesmo solo, de acordo com o teste $t$ pareado.

et al. (1991) e Blair (2000). Ceddia et al. (1999) registraram aumentos na estabilidade de macroagregados em solo arenoso após cinco anos sem queima do canavial. Graham et al. (2002a) mediram o mesmo efeito em solo argiloso depois de cinqüenta e nove anos. Souza et al. (2005) também mediram esse efeito em solo de textura média após três anos de manejo.

A formação dos agregados é influenciada pelas frações mineral e biológica. Esses fatores interagem entre si determinando a relação entre a concentração da MOS e a estabilidade dos agregados, uma relação altamente dependente do teor de argila (Feller \& Beare, 1997). Esses autores citaram o estudo de Douglas \& Goss (1982), os quais mostraram que solos com maiores concentrações de argila necessitam de maiores concentrações de matéria orgânica para atingir o mesmo nível de estabilidade de agregados dos solos com menores concentrações de argila. Dominy et al. (2002) observaram diminuição da MOS em relação ao teor original, em dois solos distintos quanto à textura, cultivados com cana-de-açúcar por longo período. No solo argiloso, o novo equilíbrio da MOS ficou muito acima daquele do solo arenoso. Isso foi atribuído à proteção que a argila proporciona à MOS e, consequentemente, aos agregados do solo, que se estabilizaram em nível muito maior do que no solo pobre em argila.

Graham et al. (2002a) verificaram aumento na estabilidade de agregados após a supressão da queima do canavial, indicando a importância do aumento no nível da MOS. Por outro lado, a aplicação de fertilizantes resultou em diminuição da estabilidade. Em experimento de laboratório, demonstraram que a aplicação de cátion trocável bivalente - $\mathrm{Ca}(\mathrm{OH})_{2}$ - promoveu aumento na estabilização, e o contrário com aplicação de cátion trocável monovalente - KOH. Os autores citaram van Antwerpen \& Meyer (1998), os quais sugeriram que a aplicação anual de K causa lixiviação de Ca e Mg da superfície, e isso favoreceria a dispersão e o decréscimo da estabilidade. Assim, a diminuição da estabilidade dos agregados do solo (0-2,5 cm) no experimento de campo foi atribuída ao aumento na concentração de $\mathrm{K}^{+}+\mathrm{Na}^{+}$após a fertilização.

Importante efeito foi comprovado quanto à incorporação dos resíduos ao solo. Segundo Wood (1991) e Blair (2000), a incorporação e a conseqüente movimentação do solo resultaram em decréscimo no teor de $\mathrm{C}$ e redução na estabilidade de macroagregados estáveis em água, em relação à adição de resíduos sem incorporação. $\mathrm{O}$ decréscimo no teor de $\mathrm{C}$ após 
revolvimento do solo é devido ao aumento na taxa de decomposição causada pela quebra dos macroagregados e aumento na intensidade e no número de ciclos úmidos e secos (Syers \& Craswell, 1994; Graham et al., 2002a; Six et al., 2004). Outro fator de aumento na mineralização da MOS de solos cultivados é a entrada de maior quantidade de $\mathrm{O}_{2}$, criando um ambiente mais oxidativo e favorecendo a atividade microbiana (Reicosky, 2002).

A essa associação entre manutenção dos resíduos vegetais e o não-revolvimento do solo é atribuído o aumento do teor de MOS e o melhoramento da estrutura de solos sob plantio direto. Maior concentração de macroagregados foi medida em um solo arenoso sob plantio direto, em relação ao plantio convencional, após treze anos de manejo (Beare et al., 1994). O mesmo efeito de manejo foi registrado por Castro Filho et al. (2002) em solo argiloso após vinte e um anos de manejo, e por Palmeira et al. (1999) após dez anos em solo arenoso. Six et al. (2002) relataram diversos trabalhos da mesma natureza realizados em regiões de clima temperado e tropical, enfatizando aumento no teor de MOS e estabilidade do solo devido ao manejo conservacionista em relação ao convencional. Aumento no teor de $\mathrm{C}$ e aumento na estrutura do solo estão de acordo com diversos estudos de solos tropicais, mesmo que com diferentes métodos de determinação da estabilidade estrutural (Feller et al., 1996; Feller \& Beare, 1997).

Dominy et al. (2002) relataram perdas de solo e nutrientes por escorrimento superficial ao medirem baixa estabilidade de agregados em solo cultivado com cana sob manejo com queima na África do Sul. Destacaram a necessidade da conversão ao manejo sem queima com deposição de resíduos ao solo para reverter essa situação. De acordo com Feller \& Beare (1997), o aumento no estoque de MOS desempenha papel fundamental na estabilização dos agregados; mas a agregação também aumenta a estocagem de MOS por meio da diminuição da perda de solo via erosão.

\section{Densidade do solo}

A menor densidade de solo foi observada no LVdf, que apresentou o menor teor de areia e o maior teor de argila. $\mathrm{O}$ gradiente de densidade prosseguiu com a seqüência RQo e PVAd, ou seja, solos com altos teores de areia. As amplitudes de densidade foram: 1,21$1,44 \mathrm{~kg} \mathrm{dm}^{-3}$ no LVdf; $1,43-1,76 \mathrm{~kg} \mathrm{dm}^{-3}$ no PVAd e 1,44-1,72 kg dm ${ }^{-3}$ no RQo. Ocorreram compactações significativas nas camadas superficiais (0-10 e 10$20 \mathrm{~cm}$ ) nos solos arenosos (PVAd e RQo) sob o manejo sem queima. Esses efeitos ocorreram ora nas linhas, ora nas entrelinhas de plantio (Figura 4). Solos de textura média e grosseira, com teor de silte menor que $400 \mathrm{~g} \mathrm{~kg}^{-1}$, são mais susceptíveis à compactação (Diebold, 1954). Por outro lado, aqueles de textura fina não podem ser compactados às densidades máximas no mesmo nível dos de textura grosseira. Isso ocorre porque os solos de textura fina têm, proporcionalmente, mais espaço com microporos, que são resistentes à compactação (Howard et al., 1981; Seixas, 2002).

Braida et al. (2006) concluíram experimentalmente, em ensaio Proctor, que, com o aumento do teor de C orgânico, ocorreram diminuição da densidade máxima do solo e aumento da umidade necessária para atingila. No entanto, o efeito da matéria orgânica depende da granulometria do solo. Em solo franco-arenoso, o efeito do $\mathrm{C}$ orgânico em reduzir a densidade máxima foi 2,3 vezes superior ao efeito em solo argiloso. Segundo os autores, isso ocorreu porque a área superficial específica da matéria orgânica é muito maior do que da areia, e essa diferença entre área superficial é menor em relação à argila. Dessa forma, a matéria orgânica é mais eficiente em reduzir o efeito lubrificante da água entre as partículas minerais em solo arenoso. Em solo argiloso, a interação entre as partículas orgânicas e minerais é maior, o que resulta em menor disponibilidade da matéria orgânica para interagir com a água adicionada ao solo.

Wood (1991) encontrou, a partir do segundo ano de tratamento de cana sem queima, em sete solos da Austrália, densidade $7 \%$ maior (até $14 \mathrm{~cm}$ ), em média, em relação ao tratamento de colheita após queima, observando que essas diferenças foram maiores nas entrelinhas de plantio, local de passagem das rodas das máquinas empregadas na colheita. Villegas et al. (1998) registraram aumento de 1,17 para $1,33 \mathrm{~kg} \mathrm{dm}^{-3}$ na densidade de um solo arenoso em Cuba após um período de 24 anos de colheita mecanizada sem queima do canavial. Braunack \& Peatey (1999) comprovaram, experimentalmente, aumentos significativos na densidade de solos de textura média a argilosa até $25 \mathrm{~cm}$, ocasionados pelo uso de máquinas na colheita da cana.

Souza et al. (2005) observaram maior densidade de um solo com textura média quando submetido à colheita mecanizada da cana sem queima, comparado à colheita manual e com queima. A compactação do solo pela máquina colhedora ocorreu até a profundidade de $20 \mathrm{~cm}$. Quando a palhada foi incorporada até $30 \mathrm{~cm}$, houve diminuição da densidade do solo até essa profundidade, comparado ao solo sem incorporação da palhada. Fernandes \& Galloway (1987) mediram maior compactação e menor porosidade total, na camada 10-20 cm, em relação à camada 0-10 cm de solo. Relacionaram esse fato à concentração de resíduos orgânicos na superfície do solo. Concluíram que a cobertura morta proporcionou efeito protetor contra o impacto das gotas de chuva, evitando o contato direto do rodado, permitindo maior dissipação da energia de pressão, e permitiu a recuperação da estrutura do solo. Seixas et al. (1995) detectaram redução na compactação do solo por máquina colhedora quando esta trafegava sobre camada de resíduos da colheita de madeira. Cobertura de galhos e acículas em quantidades de 10 e $20 \mathrm{~kg} \mathrm{~m}^{-2}$ reduziram em cerca de $40 \%$ o incremento da densidade do solo observado em parcelas sem cobertura. 

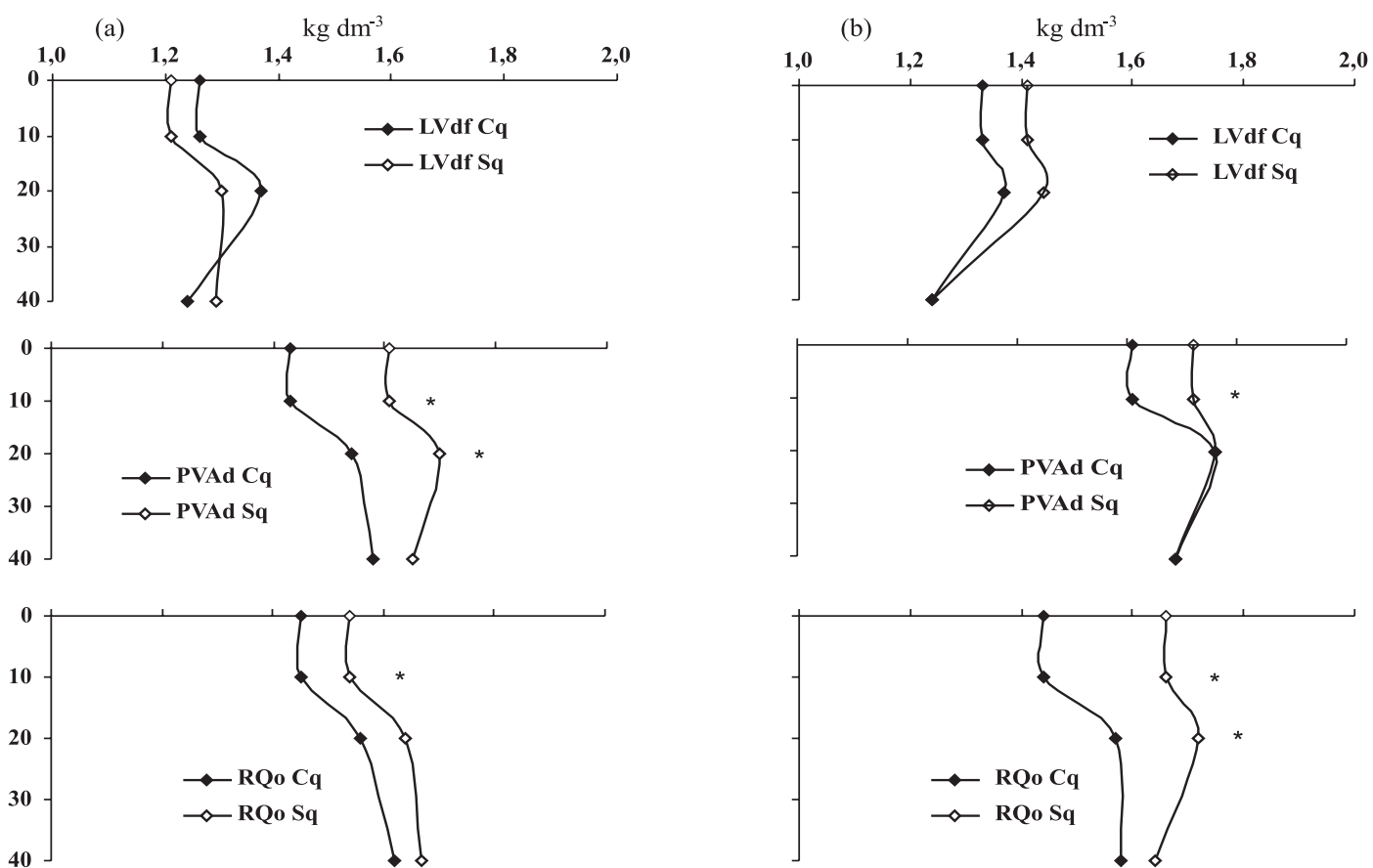

Figura 4. Densidade do solo no Latossolo Vermelho distroférrico (LVdf), Argissolo Vermelho-Amarelo distrófico (PVAd) e Neossolo Quartzarênico órtico (RQo) sob os manejos com queima (Cq) e sem queima (Sq) de canavial nas diferentes profundidades. (a) linhas de plantio, (b) entrelinhas de plantio. * Diferença estatística entre tratamentos na mesma profundidade, de acordo com o teste t pareado.

Braida et al. (2006) concluíram do ensaio Proctor que, quanto maior for a quantidade de palha sobre o solo, menor é a densidade de solo atingida. Devido à sua baixa densidade, associado à susceptibilidade à deformação e elasticidade, a palha sobre o solo atenuou as cargas aplicadas e dissipou até $30 \%$ da energia de compactação.

A maior estabilidade à ruptura de agregados, conforme ocorrido nos solos cobertos pela palhada, é fator de resistência à compactação, pois, sem a ruptura, não há individualização de partículas nem preenchimento de microporos com material fino. Segundo Ceddia et al. (1999), o manejo com queima causou a destruição dos agregados e a individualização das partículas, resultando em aumento da densidade e conseqüente diminuição da microporosidade e porosidade total do solo. Diminuição da microporosidade e adensamento superficial ocorreram também em Latossolo de textura média sobre plantio direto, em relação ao plantio convencional (Vieira \& Muzilli, 1984), causas de diminuição da velocidade de infiltração instantânea de água (Vieira \& Muzilli, 1984; Ceddia et al., 1999).

Menores taxas de infiltração não ocasionam necessariamente maior escorrimento superficial, pois variáveis como resistência do solo à desagregação pelo impacto de gotas de chuva e a cobertura vegetal passam a desempenhar papel importante na quantidade de água que penetra no solo por unidade de tempo (Vieira \& Muzilli, 1984; Shukla et al., 2003; Lado et al., 2004).

\section{CONCLUSÕES}

1. A colheita mecanizada da cana-de-açúcar sem queima do canavial possibilitou o aporte de densa camada de palhada sobre o solo, distribuída uniformemente nas entrelinhas de plantio.

2. A decomposição da palhada depositada proporcionou aumento no teor e no estoque de matéria orgânica no Latossolo Vermelho e no Neossolo Quartzarênico, que passaram a funcionar como dreno de $\mathrm{C}$ e $\mathrm{N}$ atmosféricos.

3. Maior teor de matéria orgânica favoreceu o aumento de estabilidade de agregados no Latossolo Vermelho e no Neossolo Quartzarênico, expresso pelo maior teor de macroagregados e menor teor de microagregados estáveis em água.

4. O uso de máquinas para a realização da colheita causou aumento na densidade do solo nas camadas superficiais $(0-10 \mathrm{~cm}$ e $10-20 \mathrm{~cm})$ do Argissolo Vermelho-Amarelo e do Neossolo Quartzarênico. 


\section{AGRADECIMENTOS}

Os autores agradecem à FAPESP pelo financiamento do projeto de pesquisa (processo 98/12648-3) e pela concessão da bolsa de doutoramento ao primeiro autor (processo 98/13281-6); ao Centro de Tecnologia Canavieira e às usinas São Martinho, Da Pedra e Santa Luiza pela disponibilização das áreas e pelas facilidades proporcionadas à realização deste trabalho.

\section{LITERATURA CITADA}

BALL-COELHO, B.; TIESSEN, H.; STEWART, J.W.B.; SALCEDO, I.B. \& SAMPAIO, E.V.S.B. Residue management effects on sugarcane yield and soil properties in northeastern Brazil. Agron. J., 85:1004-1008, 1993.

BAYER, C.; MIELNICZUK, J. \& MARTIN-NETO, L. Efeito de sistemas de preparo de cultura na dinâmica da matéria orgânica e na mitigação das emissões de $\mathrm{CO}_{2}$. R. Bras. Ci. Solo, 24:599-607, 2000.

BEARE, M.H.; HENDRIX, P.F. \& COLEMAN, D.C. Waterstable aggregates and organic matter fractions in conventional- and no-tillage soils. Soil Sci. Soc. Am. J., 58:777-786, 1994.

BLAIR, N. Impact of cultivation and sugar-cane green trash management on carbon fractions and aggregate stability for a Chromic Luvisol in Queensland, Australia. Soil Till. Res., 55:183-191, 2000.

BRAIDA, J.A.; REICHERT, J.M.; VEIGA, M. \& REINERT, D.J. Resíduos vegetais na superfície e carbono orgânico do solo e suas relações com a densidade máxima obtida no ensaio Proctor. R. Bras. Ci. Solo, 30:605-614, 2006.

BRAUNACK, M.V. \& PEATEY, T.C. Changes in soil physical properties after one pass of sugarcane haulout unit. Aust. J. Exp. Agric., 39:733-742, 1999.

BRONICK, C.J. \& LAL, R. Soil structure and management: A review. Geoderma, 124:3-22, 2005.

CASTRO FILHO, C.; LOURENÇO, A.; GUIMARÃES, M.F. \& FONSECA, I.C.B. Aggregate stability under different soil management systems in a red latosol in the State of Paraná, Brazil. Soil Till. Res., 65:45-51, 2002.

CEDDIA, M.B.; ANJOS, L.H.C.; LIMA, E.; RAVELLI NETO, A. \& SILVA, L.A. Sistemas de colheita da cana-de-açúcar e alterações nas propriedades físicas de um solo Podzólico Amarelo no Estado do Espírito Santo. Pesq. Agropec. Bras., 34:1467-1473, 1999.

CERRI, C.C.; FELLER, C. \& CHAUVEL, A. Evolução das principais propriedades de um latossolo vermelho escuro após desmatamento e cultivo por doze e cinqüenta anos com cana-de-açúcar. Cah. ORSTOM, Sér. Pedol., 26:3750, 1991.

CORAZZA, E.J.; SILVA, J.E.; RESCK.; D.V.S. \& GOMES, A.C. Comportamento de diferentes sistemas de manejo como fonte ou depósito de carbono em relação à vegetação de cerrado. R. Bras. Ci. Solo, 23:425-432, 1999.
DIEBOLD, C.H. Permeability and intake rates of medium textured soils in relation to silt content and degree of compaction. Soil Sci. Soc. Am. J., 18:339-343, 1954.

DOMINY, C.S.; HAYNES, R.J. \& van ANTWERPEN, R. Loss of soil organic matter and related soil properties under long-term sugarcane production on two contrasting soils. Biol. Fertil. Soils., 36:350-356, 2002.

DOUGLAS, J.T. \& GOSS, M.J. Stability and organic matter content of surface soil aggregates under different methods of cultivation and in grassland. Soil Till. Res., 2:155-175, 1982.

ELLERT, B.H. \& BETTANY, J.R. Calculation of organic matter and nutrients stored in soils under contrasting management regimes. Can. J. Soil Sci., 75:529-538, 1995.

EMPRESA BRASILEIRA DE PESQUISA AGROPECUÁRIA EMBRAPA. Sistema brasileiro de classificação de solos. Brasília, 1999. 412p.

ESTADOS UNIDOS. Departament of Agriculture. Soil Survey Division. Soil Conservation Service. Soil Survey Staff. Soil taxonomy: A basic system of soil classification for making and interpreting soil surveys. Washington, 1975. 754p. (Agriculture Handbook, 436)

FELLER, C. \& BEARE, M.H. Physical control of soil organic matter dynamics in tropical land-use systems. Geoderma, 79:49-67, 1997.

FELLER, C.; ALBRECHT, A. \& TESSIER, D. Aggregation and organic carbon storage in kaolinitic and smectitic soils. In: CARTER, M.R. \& STEWART, B.A., eds. Structure and organic matter storage in agricultural soils. Advances in soil science. Boca Raton, CRC Press, 1996. p.309-359.

FELLER, C.; ALBRECHT, A.; BLANCHART, E.; CABIDOCHE, Y.M.; CHEVALLIER, T.; HARTMANN, C.; ESCHENBRENNER, V.; LARRÉ-LARROUY, M-C. \& NDANDOU, J.F. Soil organic carbon sequestration in tropical areas. General considerations and analysis of some edaphic determinantes for Lesser Antilles soils. Nutr. Cycling Agroecosyst., 61:19-31, 2001.

FERNANDES, B. \& GALLOWAY, H.M. Efeito das rodas do trator em propriedades físicas de dois solos. Ceres, 34:562$568,1987$.

GRAHAM, M.H.; HAYNES, R.J. \& MEYER, J.H. Changes in soil chemistry and aggregate stability induced by fertilizer applications, burning and trash retention on a long-term sugarcane experiment in South Africa. Eur. J. Soil Sci., 53:589-598, 2002a.

GRAHAM, M.H.; HAYNES, R.J. \& MEYER, J.H. Soil organic matter content and quality: Effects of fertilizer applications, burning and trash retention on a long-term sugarcane experiment in South Africa. Soil Biol. Biochem., 34:93-102, 2002b.

HOWARD, R.F.; SINGER, M.J. \& FRANTZ, G.A. Effects of soils properties, water content and compactive effort on the compaction of selected California forest and range soils. Soil Sci. Soc. Am. J., 45:2313-2316, 1981.

INDICADORES. Disponível em: <http://www.ibge.gov.br/> Acesso em 25 set. 2005. 
KEMPER, W.D. \& ROSENAU, R.C. Aggregate stability and size distribution. In: KLUTE, A., ed. Methods of soil analysis: Physical and mineralogical methods. 2.ed. Madison, ASA/SSSA, 1986. p.425-442.

LADO, M.; PAZ, A. \& BEM-HUR, M. Organic matter and aggregate size interactions in infiltration, seal formation, and soil loss. Soil Sci. Soc. Am. J., 68:935-942, 2004.

LAL, R. Soil aggregation and $\mathrm{C}$ sequestration. In: LAL, R.; KIMBLE, J.M. \& STEWART, B.A., eds. Global climate change and tropical ecossystems. Advances of soil science. Boca Raton, CRC Press, 1999. p.317-329.

LAL, R. Soil carbon sequestration to mitigate climate change. Geoderma, 123:1-22, 2004

LEPSCH, I.F.; SILVA, N.M. \& ESPIRONELO, A. Relação entre matéria orgânica e textura de solos sob cultivo de algodão e cana-de-açúcar, no estado de São Paulo. Bragantia, 41:231-236, 1982.

LEPSCH, I.F.; MENK, J.R.F. \& OLIVEIRA, J.B. Carbon storage and other properties of soils under agriculture and natural vegetation in São Paulo State, Brazil. Soil Use Manag., 10:34-42, 1994.

NELSON, D.W. \& SOMMERS, L.E. Total carbon, organic carbon and organic matter. In: PAGE, A.L.; MILLER, R.H \& KEENEY, D.R., eds. Methods of soil analysis: Chemical and microbiological properties. 2.ed. Madison, ASA/SSSA, 1986. p.539-579.

NOBLE, A.D.; MOODY, P. \& BERTHELSEN, S. Influence of changed management of sugarcane on some soil chemical properties in the humid wet tropics of north Queensland. Aust. J. Soil Res., 41:1133-1144, 2003.

OLIVEIRA, J.B. \& PRADO, H. Levantamento pedológico semidetalhado do Estado de São Paulo: quadrícula de Ribeirão Preto. II: memorial descritivo. Campinas, Instituto Agronômico de Campinas, 1987. 133p. (Boletim Científico, 7)

OLIVEIRA, M.W.; TRIVELIN, P.C.O.; PENATTI, C.P. \& PICCOLO, M.C. Decomposição e liberação de nutrientes da palhada de cana-de-açúcar em campo. Pesq. Agropec. Bras., 34:2359-2362, 1999.

ORLANDO FILHO, J.; ROSSETO, R.; MURAOKA, T. \& ZOTELLI, H.B. Efeitos do sistema de despalha (cana crua x cana queimada) sobre algumas propriedades do solo. STAB-Açúcar, Álcool Subpr., 16:30-34, 1998.

PALMEIRA, P.R.T.; PAULETTO, E.A.; TEIXEIRA, C.F.A.; GOMES, A.S. \& SILVA, J.B. Agregação de um Planossolo submetido a diferentes sistemas de cultivo. R. Bras. Ci. Solo, 23:189-195, 1999.

REICOSKY, D.C. Long-term effect of moldboard plowuing on tillage-induced $\mathrm{CO}_{2}$ loss. In: KIMBLE, J.M.; LAL, R. \& FOLLETT, R.F., eds. Agricultural practices and policies for carbon sequestration in soil. Boca Raton, CRC Press, 2002. p.87-97.

ROBINSON, J.B.D. Soil particle-size fractions and nitrogen mineralization. J. Soil Sci., 18:109-117, 1967.
SÁ, J.C.M.; CERRI, C.C.; DICK, W.A.; LAL, R.; VENSKE, S.P.; PICCOLO, M.C. \& FEIGL, B.J. Organic matter dynamics and carbon sequestration rates for a tillage chronosequence in a Brazilian Oxisol. Soil Sci. Soc. Am. J., 65:1486-1499, 2001.

SAS Insitute Inc. SAS/STAT User's guide. Version 6. 4.ed. Cary, 1990. 2v. 1789p.

SEIXAS, F. Efeitos físicos da colheita mecanizada de madeira sobre o solo. In: GONÇALVES, J.L.M. \& STAPE, J.L., eds. Conservação e cultivo de solos para plantações florestais. Piracicaba, IPEF, 2002. p.313-350.

SEIXAS, F.; McDONALD, T.P.; STOCKES, B.J. \& RAPER R.L. Effect of slash on forwarder soil compaction. In: ANNUAL MEETING OF THE COUNCIL ON FOREST ENGINEERING, 18., Cashiers, 1995. Proceedings. Cashiers, 1995. p.77-86.

SHUKLA, M.K.; LAL, R.; OWENS, L.B. \& UNKEFER, P. Land use management impacts on structure and infiltration characteristics of soils in the north Appalachian region of Ohio. Soil Sci., 168:167-177, 2003.

SIX, J.; BOSSUYT, H.; DEGRYZE, S. \& DENEF, K. A history of research on the link between (micro)aggregates, soil biota, and soil organic matter dynamics. Soil Till. Res., 79:7-31, 2004

SIX, J.; ELLIOTT, E.T. \& PAUSTIAN, K. Soil structure and soil organic matter: II. A normalized stability index and the effect of mineralogy. Soil Sci. Soc. Am. J. 64:10421049, 2000.

SIX, J.; FELLER, C.; DENEF, K.; OGLE, S.M.; SÁ, J.C.M. \& ALBRECHT, A. Soil organic matter, biota and aggregation in temperate and tropical soils - effects of no-tillage. Agronomie, 22:755-775, 2002.

SOUZA, Z.M.; PRADO, R.M.; PAIXÃO, A.C.S. \& CESARIN, L.G. Sistemas de colheita e manejo da palhada de canade-açúcar. Pesq. Agropec. Bras., 40:271-278, 2005.

SYERS, J.K. \& CRASWELL, E.T. Role of organic matter in sustainable agricultural systems. In: LEFROY, R.D.B.; BLAIR, G.J. \& CRASWELL, E.T., eds. Soil organic matter management for sustainable agriculture. ACIAR, 56., Ubon, 1994. Proceedings. Camberra, 1994. p.7-14.

van ANTWERPEN, R. \& MEYER, J.H. Soil degradation II: Effect of trash and inorganic fertilizer application on soil strength. Proc. South African Sugar Tech. Assoc., 72:152258,1998 .

VIEIRA, M.J. \& MUZILLI, O. Características físicas de um Latossolo Vermelho-Escuro sob diferentes sistemas de manejo. Pesq. Agropec. Bras., 19:873-882, 1984.

VILlEGAS, R.; CHANG, R.M. \& GONZÁLES, M. Sostenibilidad del agroecosistema y evolución de características biogeoquímicas en estudios de larga duración con caña de azúcar. Cuba Caña, 2:11-17, 1998.

WOOD, A.W. Management of crop residues following green harvesting of sugarcane in north Queensland. Soil Till. Res., 20:69-85, 1991. 